\title{
Electrochemical capacitor of magnetite in aqueous electrolytes
}

\author{
Nae-Lih $\mathrm{Wu}^{\mathrm{a}}{ }^{*}$, Shi-Yu Wang ${ }^{\mathrm{a}}$, Chih-Yu Han ${ }^{\mathrm{a}}$, \\ Dien-Shi $\mathrm{Wu}^{\mathrm{b}}$, Lih-Ren Shiue ${ }^{\mathrm{c}}$ \\ ${ }^{a}$ Department of Chemical Engineering, National Taiwan University, Taipei 106, Taiwan, ROC \\ ${ }^{\mathrm{b}}$ STIC, National Science Council, 106 Hoping E. Road, Section 2, Taipei 106, Taiwan, ROC \\ ${ }^{\mathrm{c}}$ Luxon Energy Devices Corporation, Room 529, Bldg. 53, 195 Section 4, Chung Hsing Road, \\ Chutung, Hsinchu 310, Taiwan, ROC
}

Received 13 June 2002; accepted 29 August 2002

\begin{abstract}
The capacitive behaviours of magnetite nanocrystallites, along with conductive carbon black additive, in aqueous electrolytes, including sodium sulphite, sulphate, chloride, and phosphate, and potassium hydroxide, have been characterised by means of cyclic voltammetry and chrono-potentiometry. The behaviour can be categorised into three groups. Sodium sulphate and chloride electrolytes give capacitances $\left(\sim 5 \mathrm{~F} / \mathrm{g}-\mathrm{Fe}_{3} \mathrm{O}_{4}\right)$ close to the space-charge capacitance of the oxide. Potassium hydroxide and sodium phosphate gave rise to a higher capacitance $(\sim 7 \mathrm{~F} / \mathrm{g})$ which can in part be attributed to a surface redox reaction which involves hydroxide ions. Sodium sulphite results in the highest capacitances, which depend heavily on the dispersion of magnetite crystallites on the conductive matrix and range from $\sim 30$ to $510 \mathrm{~F} /$ $\mathrm{g}-\mathrm{Fe}_{3} \mathrm{O}_{4}$ with an operation voltage range of $1.2 \mathrm{~V}$. Correlation between rest potential and anion-concentration gives strong indication of potential-determining process which involve either $\mathrm{OH}$ under extremely alkaline conditions $(\mathrm{pOH}<3)$ or $\mathrm{SO}_{3}{ }^{2-}$ in the sulphite electrolyte. (C) 2002 Elsevier Science B.V. All rights reserved.
\end{abstract}

Keywords: Electrochemical capacitor; Magnetite; Pseudo-capacitance; Nanocrystalline electrode; Sulfite electrolyte

\section{Introduction}

Pseudo-capacitance (PC) [1-7] denotes the charge-storage mechanism which results from faradaic reactions involving only surface or adsorbed species at the electrodelelectrolyte interface. The mechanism typically gives capacitances 10-100 times greater than electric double-layer capacitance (EDLC) $[1,2,8,9]$ per unit area, and was first exhibited by a handful of precious metals and their oxides, such as $\mathrm{Pt}, \mathrm{IrO}_{2}$ and $\mathrm{RuO}_{2}$ [1-7]. Applications of these materials have, however, been hindered by their high costs. Research has continuously been carried out to find less expensive PC electrodes [10-13]. Specific capacitances greater than $100 \mathrm{~F} / \mathrm{g}$ in aqueous electrolytes have recently been reported $[14,15]$ for several solution-derived mixed iron oxide surface-layers or thin films that consist of mainly $\mathrm{Fe}_{3} \mathrm{O}_{4}$. In the work reported here, the capacitive behaviour of well-defined magnetite particulate electrodes has been characterised in several aqueous electrolytes which include

\footnotetext{
* Corresponding author. Tel.: +886-2-2263-7158; fax: +886-2-2362-3040.

E-mail address: nlw001@ccms.ntu.edu.tw (N.-L. Wu).
}

sodium sulphite, sulphate, chloride and phosphate, and potassium hydroxide.

\section{Experimental}

Magnetite has a very limited conductivity and preliminary tests showed that it was necessary to combine the oxide with conductive additives in order to obtain significant capacitance. Two types of composite electrodes consisting of magnetite and conductive carbon black (CB; VULCAN ${ }^{\circledR}$ XC72, Cabot Corp., USA) were prepared for characterisation in this work. The first type, which will be referred to as the 'mixed' electrode, consists of magnetite particles and CB powder mixed by mechanical grinding. The magnetite particles were synthesised by the electrocoagulation process described by Tsouris et al. [16]. This process involves immersing two plates of carbon steel in a $0.04 \mathrm{M} \mathrm{NaCl}_{(\mathrm{aq})}$ solution, and applying a voltage $(30 \mathrm{~V})$ to the electrodes at room temperature. The resulting magnetite particles were then thoroughly washed with de-ionised water and finally vacuum-dried. The second type of composite electrode, referred to as the 'coprecipitated' electrode, was synthesised 
by refluxing conductive carbon black powders in an aqueous solution of $\mathrm{FeSO}_{4}, 1 \mathrm{M} \mathrm{KOH}$ and $0.08 \mathrm{M} \mathrm{KNO}_{3}$ at $95{ }^{\circ} \mathrm{C}$ for $30 \mathrm{~min}$ [17]. In this case, as confirmed by electron microscopic analyses and magnetic experiments, magnetite crystallites were deposited in situ on CB to form magnetite/ carbon composite powders. The magnetite content in the powder was determined by inductively coupled plasma (ICP) analysis.

To prepare the electrodes, mixtures which comprised selected compositions of magnetite, $\mathrm{CB}$, the coprecipitated composite powder and binder (PTFE, 4 wt.\%) were ground in ethanol, and the resulting mixtures were pressed on to $\mathrm{Ti}$ meshes, which served as current-collectors. All electrodes subjected to characterisation had an active geometric area of $\sim 1 \mathrm{~cm}^{2}$. Electrochemical characterisation was carried by means of an electrochemical analyser (Eco Chemie PGSTAT30). Cyclic voltammograms (CVs) were acquired with a two-electrode configuration which was comprised of two plane electrodes of the same composition $1 \mathrm{~cm}$ apart, while single-electrode $\mathrm{CVs}$ were recorded with a threeelectrode configuration with an $\mathrm{Ag} \mid \mathrm{AgCl}$ lsaturated $\mathrm{KCl}$ (EG\&G, $197 \mathrm{mV}$ versus $\mathrm{SHE}$ at $25^{\circ} \mathrm{C}$ ) reference electrode. For microstructural characterisation, nitrogen adsorption (ASAP2000, Micromeritics) was conducted to determine the BET surface-area, while X-ray diffraction (XRD) was performed with a Mac-Science/MXP diffractometer with $\mathrm{Cu}$ $\mathrm{K} \alpha$ radiation.

\section{Results and discussion}

X-ray diffraction shows that both the electrocoagulationand coprecipitation-derived oxide powders contain magnetite as the predominant iron-containing species, except for a small amount ( $<5 \mathrm{~mol} \%)$ of hematite in some cases (Fig. 1). The electrocoagulation-derived magnetite powder has an average grain size of $14 \mathrm{~nm}$, as calculated from the

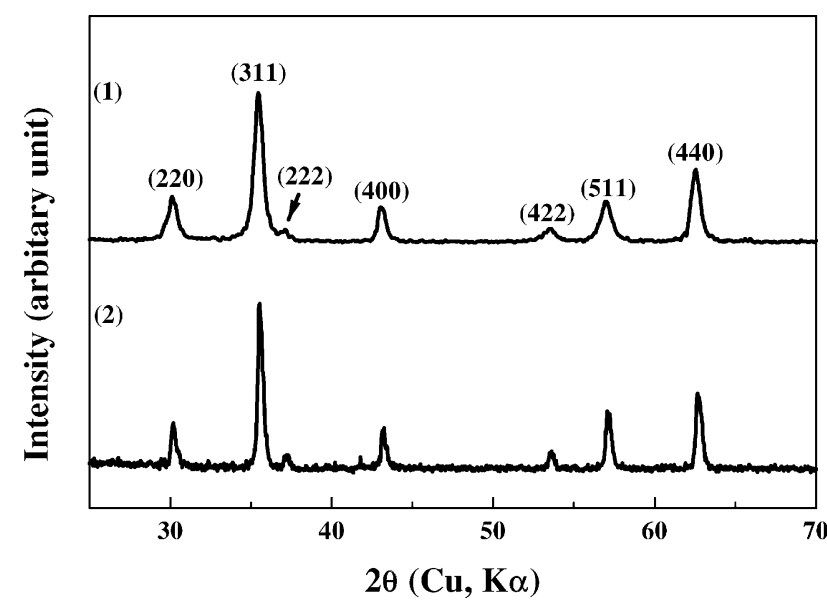

Fig. 1. XRD patterns acquired from powders synthesised, respectively, via (curve 1) electrocoagulation and (2) coprecipitation processes. The indices indicate reflections due to $\mathrm{Fe}_{3} \mathrm{O}_{4}$.

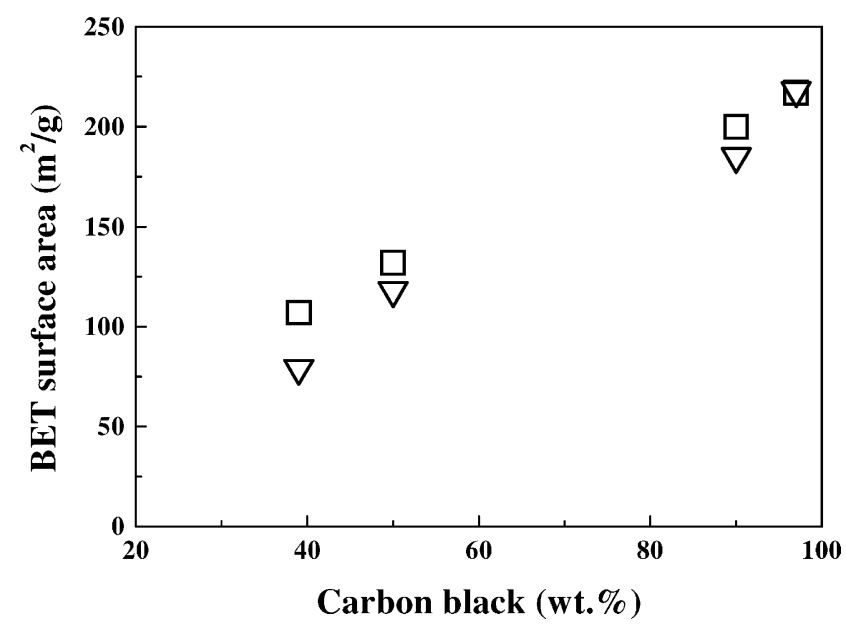

Fig. 2. Effect of carbon black (CB) content on BET surface-area of magnetite-CB composite powder prepared via coprecipitation process: $(\square)$ calculated; $(\nabla)$ measured.

Debye-Scherrer equation, based on the line-broadening of the magnetite ( 3111$)$ reflection. The BET surface-area is $34 \mathrm{~m}^{2} / \mathrm{g}$ which can be translated into a grain size of $29 \mathrm{~nm}$ for non-agglomerated, non-porous crystallites. The fact that this value is much greater than the XRD-grain size $(14 \mathrm{~nm})$ suggests agglomeration among the oxide crystallites. The coprecipitation-derived magnetite powders, on the other hand, have an XRD average grain size that increases slightly with magnetite content, i.e. from 19 to $29 \mathrm{~nm}$ for 3-61 wt.\% $\mathrm{Fe}_{3} \mathrm{O}_{4}$. The BET surface-areas of these powders increase with increasing $\mathrm{CB}$ content, i.e. with decreasing magnetite content, as shown in Fig. 2. Also plotted are the theoretical specific surface-areas for different magnetite composition based on the assumption of an unchanged surface-area of the $\mathrm{CB}$ component and non-porous, non-agglomerated magnetite crystallites. It is found that the measured surface-area matches the calculated value at a $97 \mathrm{wt} . \% \mathrm{CB}$ (or $3 \mathrm{wt} . \%$ magnetite) loading and that difference increases with decreasing CB content. This result may be interpreted in terms of a high degree of dispersion of the magnetite crystallites at $3 \mathrm{wt} . \%$, but with increasing agglomeration toward higher loadings.

Cyclic voltammograms of the mixed electrodes in aqueous electrolytes, viz. $1 \mathrm{M}$ solutions of $\mathrm{Na}_{2} \mathrm{SO}_{3}$ (Fig. 3(a)) $\mathrm{NaCl}, \mathrm{Na}_{2} \mathrm{SO}_{4}, \mathrm{KOH}$ and a saturated solution of $\mathrm{Na}_{3} \mathrm{PO}_{4}$ are shown in Fig. 3(b). In all cases, the electrodes exhibit 'mirror-image' traces characteristic of a capacitor. The sodium sulphite electrolyte gives the largest capacitance, which is 5-7 times greater than the other electrolytes, while the two neutral electrolytes, including sodium sulphate and chloride, exhibit the smallest capacitances. Based on singleelectrode CVs (Fig. 4), the electrolytes can be categorised into three groups. The first category includes sodium sulphite, which gave the largest capacitance with an operation range of $\sim 1.2 \mathrm{~V}$ (from -0.8 to $0.4 \mathrm{~V}$ versus $\mathrm{Ag} \mid \mathrm{AgCl}$ saturated $\mathrm{KCl}$, Fig 4(a)), bounded by $\mathrm{H}^{+} / \mathrm{H}_{2}$ and $\mathrm{O}_{2} / \mathrm{H}_{2} \mathrm{O}$ reactions. In addition, two shallow redox reaction 'humps' 

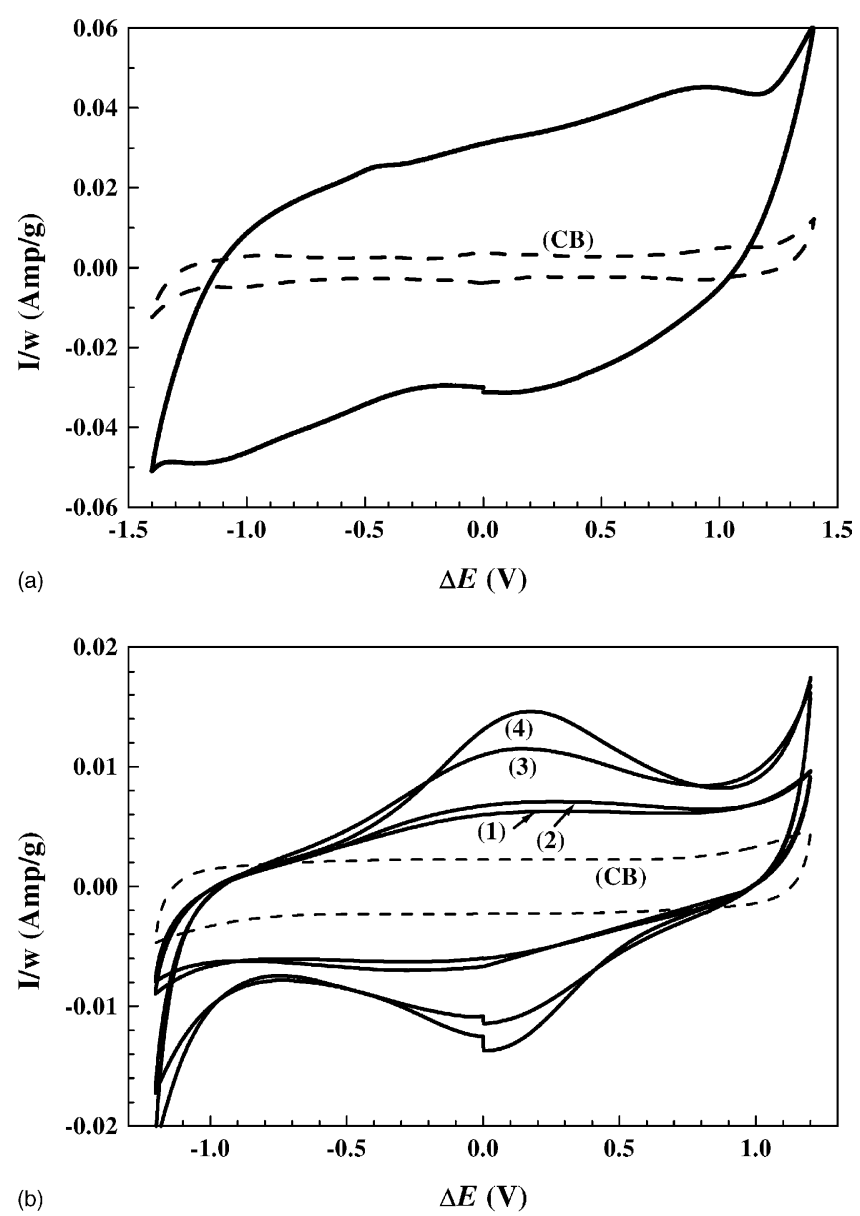

Fig. 3. Cyclic voltammograms for mixed electrodes containing magnetite:carbon black $=9: 1$ by weight in (a) $1 \mathrm{M} \mathrm{Na}_{2} \mathrm{SO}_{3}$ and (b) $1 \mathrm{M}$ $\mathrm{NaCl}$ (curve 1), $1 \mathrm{M} \mathrm{Na}_{2} \mathrm{SO}_{4}$ (curve 2), $1 \mathrm{M} \mathrm{KOH}$ (curve 3), and saturated $\mathrm{Na}_{3} \mathrm{PO}_{4}$ (curve 4). Dashed lines marked with (CB) indicate contribution of carbon black in (a) $\mathrm{Na}_{2} \mathrm{SO}_{3}$ and (b) saturated $\mathrm{Na}_{3} \mathrm{PO}_{4}$, respectively, as determined for pure carbon black electrodes (sweep rate: $2 \mathrm{mV} / \mathrm{s}$ ).

centred at -0.32 and $0.22 \mathrm{~V}$ (or -0.12 and $0.42 \mathrm{~V}$ versus SHE), respectively are evident. To our knowledge, these two reaction potentials do not match with any known redox reaction involving either iron cation or sulphite anion.

The second category includes sodium chloride and sulphate, and produce almost identical CVs (curves 1 and 2, Fig. 4(b)) with a slight increase in capacitance towards increasing negative potentials. This is characteristic of space-charge-limited capacitance for a semiconductor-electrolyte interface [19]. These two electrolytes posses an operation range of at least $1.6 \mathrm{~V}$. Potassium chloride and sodium phosphate constituted the third category, and show strong redox reaction towards negative potentials. The redox peaks appearing at the far-left (negative potential) side of the CVs involve reversible redox reactions in conjunction with the $\mathrm{H}^{+} / \mathrm{H}_{2}$ irreversible reaction.

The specific capacitance of the magnetite component in these electrolytes was determined from chrono-potential curves (Fig. 5) for charging-discharging under constantcurrent with an operation potential range of $1.2 \mathrm{~V}$. Contribu-

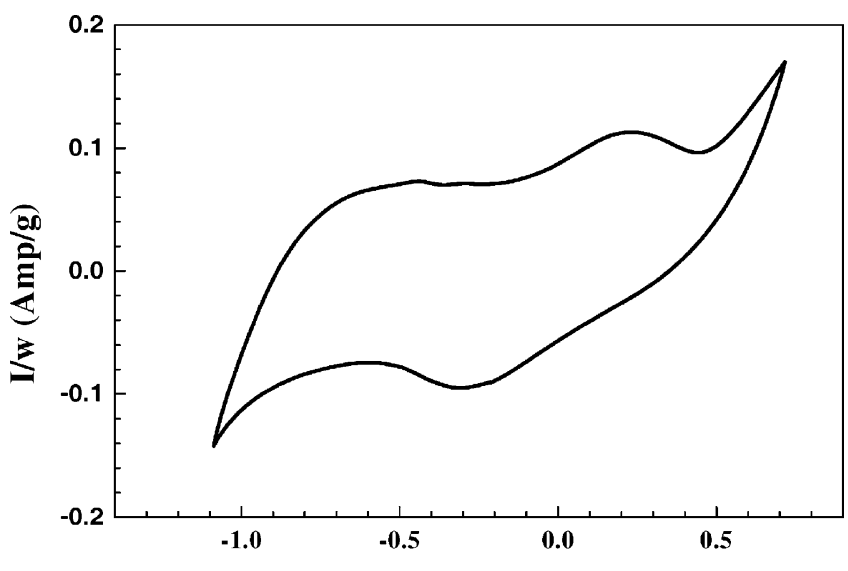

(a)

E(V) vs. $\mathrm{Ag} / \mathrm{AgCl}$

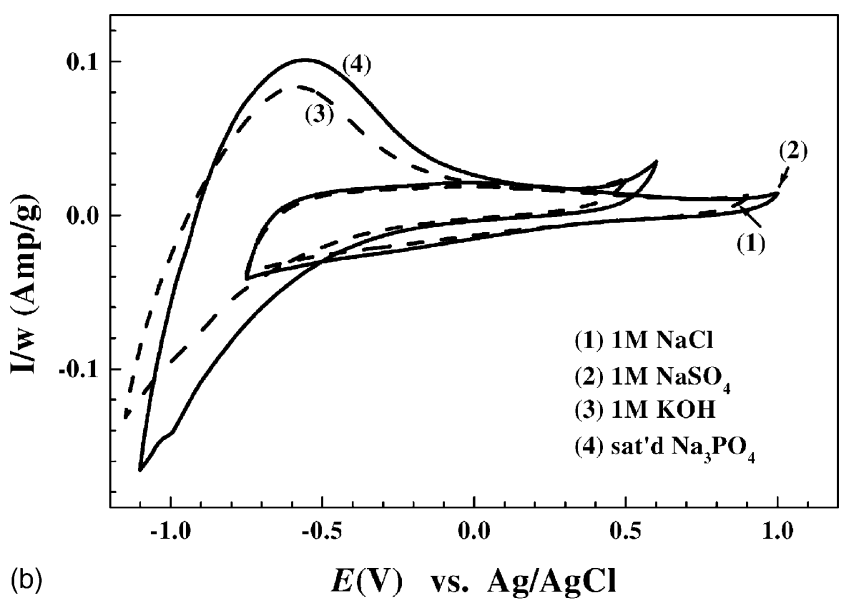

Fig. 4. Cyclic voltammograms for mixed electrodes containing magnetite:carbon black $=9: 1$ by weight in (a) $1 \mathrm{M} \mathrm{Na}_{2} \mathrm{SO}_{3}$ and (b) $1 \mathrm{M}$ $\mathrm{NaCl}$ (curve 1), $1 \mathrm{M} \mathrm{Na}_{2} \mathrm{SO}_{4}$ (curve 2), $1 \mathrm{M} \mathrm{KOH}$ (curve 3), and saturated $\mathrm{Na}_{3} \mathrm{PO}_{4}$ (curve 4) (reference electrode: $\mathrm{Agl} / \mathrm{AgCl}$ saturate $\mathrm{KCl}$; sweep rate: $2 \mathrm{mV} / \mathrm{s})$.

tions from the carbon black component were accessed from a pure CB cell in the same electrolytes and were subtracted. The capacitances based on the charging and the discharging branches of the curves are listed in Table 1. Except for the

Table 1

Effect of electrolyte on specific capacitance of magnetite in mixed electrode containing magnetite:carbon black $=9: 1$

\begin{tabular}{llc}
\hline Electrolyte & \multicolumn{2}{c}{ Specific capacitance $\left(\mathrm{F} / \mathrm{g}-\mathrm{Fe}_{3} \mathrm{O}_{4}\right)^{\mathrm{a}}$} \\
\cline { 2 - 3 } & Charging & Discharging \\
\hline $1 \mathrm{M} \mathrm{Na}_{2} \mathrm{SO}_{3}$ & 38 & 27 \\
$1 \mathrm{M} \mathrm{NaCl}$ & 4.9 & 4.9 \\
$1 \mathrm{M} \mathrm{Na}_{2} \mathrm{SO}_{4}$ & 5.3 & 5.3 \\
$1 \mathrm{M} \mathrm{KOH}_{\text {Saturated Na}} \mathrm{PO}_{4}$ & 5.8 & 5.7 \\
& 7.6 & 7.6
\end{tabular}

\footnotetext{
${ }^{a}$ Specific capacitances were calculated based on chrono-potential curves acquired under a constant charging and discharging current of $15 \mathrm{~mA} / \mathrm{g}$, with subtraction of the contribution from the carbon black component.
} 


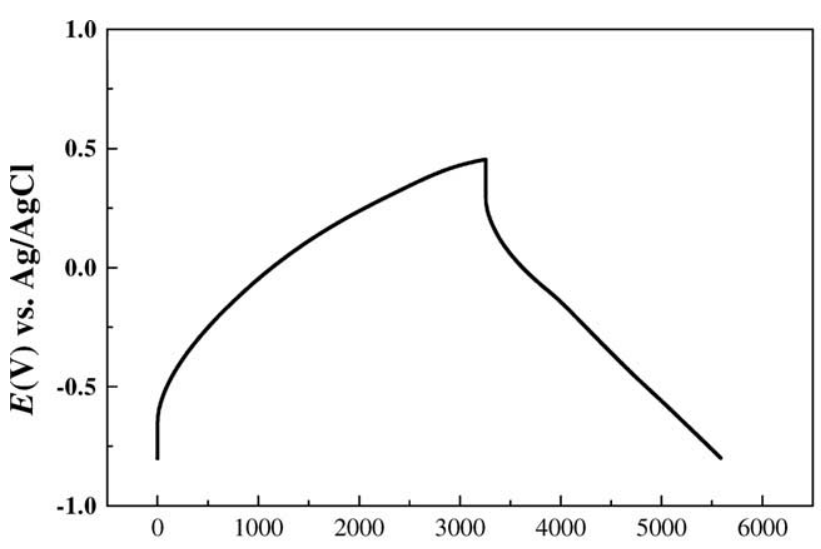

(a)

Time (sec)

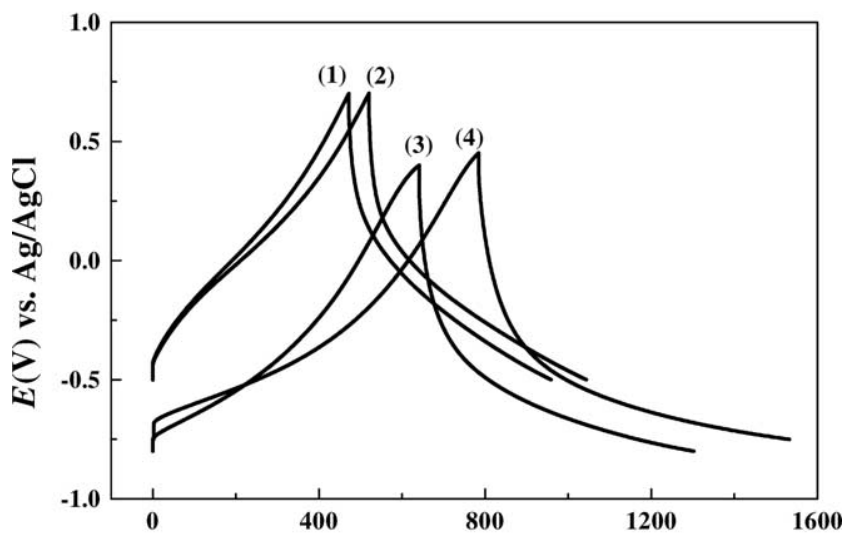

(b)

Time (sec)

Fig. 5. Chrono-potential curves under constant-current charge-discharge for individual electrodes magnetite:carbon black $=9: 1$ in (a) $1 \mathrm{M} \mathrm{Na}_{2} \mathrm{SO}_{3}$ and (b) $1 \mathrm{M} \mathrm{NaCl}$ (curve 1), $1 \mathrm{M} \mathrm{Na}_{2} \mathrm{SO}_{4}$ (curve 2), $1 \mathrm{M} \mathrm{KOH}$ (curve 3), and saturated $\mathrm{Na}_{3} \mathrm{PO}_{4}$ (curve 4) (charge/discharge current: $15 \mathrm{~mA} / \mathrm{g}$; reference electrode: $\mathrm{Ag} \mid \mathrm{AgCl}$ saturated $\mathrm{KCl})$.

sodium sulphite electrolyte, for which the test was performed with a higher practical current density $(8 \mathrm{~mA} /$ $\mathrm{cm}^{2}$ ) than for the other electrolytes $\left(1.5 \mathrm{~mA} / \mathrm{cm}^{2}\right)$, the discharging-charging efficiency is close to $100 \%$ even with the simplified cell configuration employed.

Due to the limited conductivity of magnetite, the conductive additive is expected to have a significant impact on the performance on the performance of the magnetite component as well as that of the entire electrode. Indeed, for example, the pure magnetite (i.e. without $\mathrm{CB}$ ) electrode exhibits a specific capacitance of less than $0.1 \mathrm{~F} / \mathrm{g}-\mathrm{Fe}_{3} \mathrm{O}_{4}$ in $1 \mathrm{M} \mathrm{Na}_{2} \mathrm{SO}_{3}$, while it was increased to about $30 \mathrm{~F} / \mathrm{g}-\mathrm{Fe}_{3} \mathrm{O}_{4}$ with an addition of $10 \mathrm{wt}$ \% of CB (Table 1; Fig. 6). Nevertheless, a further increase in $\mathrm{CB}$ content within the range 10 $75 \mathrm{wt} . \%$, produces no further increase in the specific capacitance of magnetite. By contrast, for the coprecipitate electrodes, the specific capacitance of magnetite content (Fig. 6), and reaches $\sim 510 \mathrm{~F} / \mathrm{g}-\mathrm{Fe}_{3} \mathrm{O}_{4}$ at 3 wt. $\% \mathrm{Fe}_{3} \mathrm{O}_{4}$ in $1 \mathrm{M} \mathrm{Na}_{2} \mathrm{SO}_{3}$ (Figs. 6 and 7).

The significant enhancement in specific capacitance by the addition of the very first $10 \mathrm{wt} . \%$ of $\mathrm{CB}$ can be under-

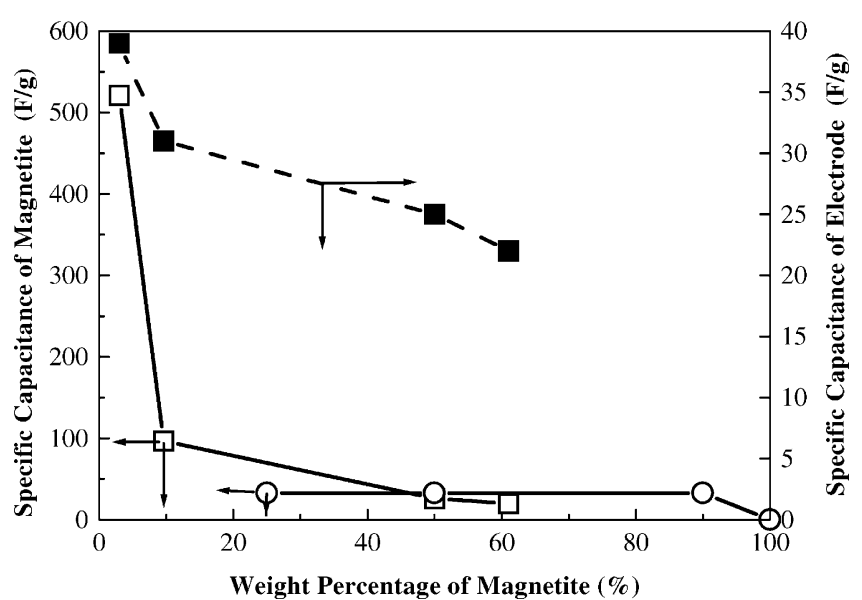

Fig. 6. Effect of magnetite loading on specific capacitance of magnetite in $(\square)$ coprecipitated electrode and $(\bigcirc)$ and the mixed electrode, and on ( specific capacitance of entire coprecipitated electrode.

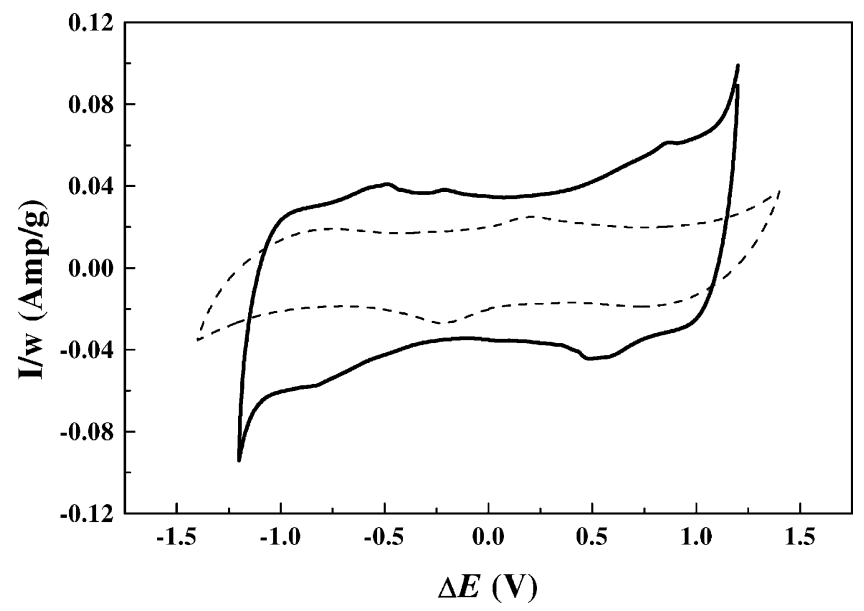

Fig. 7. Cyclic voltammograms for cell comprising coprecipitated composite powder containing $3 \mathrm{wt} . \%$ magnetite loading. Dashed line marked with $(\mathrm{CB})$ indicates contribution of carbon black (electrolyte: $1 \mathrm{M}$ $\mathrm{Na}_{2} \mathrm{SO}_{3}$, sweep rate: $2 \mathrm{mV} / \mathrm{s}$ ).

stood by considering the fact that the presence of the $\mathrm{CB}$ component reduces agglomeration among magnetite particles and, by providing a highly conductive pathway, increases the accessibility of magnetite crystallites. On the other hand, the results also indicate that the dispersion of magnetite particles within the $\mathrm{CB}$ matrix caused by mechanical grinding is limited. Greater dispersion can be obtained only by in situ deposition taking place during the coprecipitation process. Even in this case, however, a high dispersion of magnetite, and hence, a high specific capacitance, is achieved only with very low magnetite loading (e.g. $3 \mathrm{wt} . \%)$. As a result, the overall capacitance of the electrode remains no greater than $40 \mathrm{~F} / \mathrm{g}$-electrode (Fig. 6). It is clear that, in order to take full advantage of the high capacitance of magnetite, a new synthesis technique that is capable of producing high dispersion at high magnetite loading has yet to be developed. 


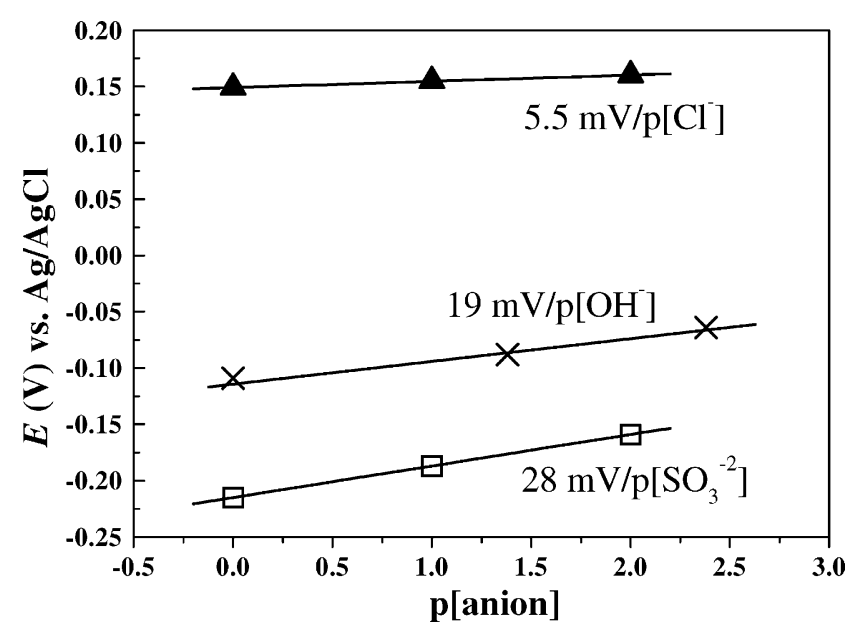

Fig. 8. The effect of anion-concentration on rest potential of mixed electrode containing magnetite:carbon black $=9: 1(\mathrm{p}[$ anion $] \equiv-\log [\operatorname{anion}])$.

Magnetite has an inversed spinel structure and is a semiconductor with a band-gap of $0.1 \mathrm{eV}$ [17]. Its conductivity originates from electron (and hole) hopping between the $\mathrm{Fe}^{2+}$ and the $\mathrm{Fe}^{3+}$ ions located at the octahedral sites. Considering the octahedral site density and the known bandgap of magnetite, its carrier density is estimated to be no greater than $2 \times 10^{21} \mathrm{~cm}^{-3}$, which is the product between $\mathrm{Fe}^{2+}$ density and $\exp (-0.1 \mathrm{eV} / 2 k T)$. Following the MottSchottky relation [18] and assuming a dielectric constant of 7.0 for the compact $\mathrm{H}_{2} \mathrm{O}$ film at the interface [9] and a voltage of $1.0 \mathrm{~V}$, a maximum space-charge capacitance at the magnetite side is calculated to be $10 \mu \mathrm{F} / \mathrm{cm}^{2}$ of real surface. This value is close to the experimentally determined capacitance of highly conductive $\mathrm{Sb}$-doped $\mathrm{SnO}_{2}$ [19], and is expected to be an upper limit that can be achieved by magnetite, which has lower carrier concentration and lower conductivity. The BET specific surface-area of the magnetite particles used in the mixed electrode, for example, is $34 \mathrm{~m}^{2}$ / g. This gives an estimated specific capacitance of $3.4 \mathrm{~F} / \mathrm{g}$ $\mathrm{Fe}_{3} \mathrm{O}_{4}$. This value is close to those in $\mathrm{NaCl}$ and $\mathrm{Na}_{2} \mathrm{SO}_{4}$ but significantly less than those in the other electrolytes, especially in $\mathrm{Na}_{2} \mathrm{SO}_{3}$ (Table 1).

The capacitance of either the mixed or the coprecipitated electrodes is found to be insensitive to alkaline cations, such as $\mathrm{K}^{+}$and $\mathrm{Na}^{+}$, but is affected dramatically by anions, as shown in Table 1. Correlation between the rest potential of the mixed electrode containing magnetite, $\mathrm{CB}=9: 1$, and the concentration of different anions has been investigated. It is found (Fig. 8) that the larger the specific capacitance, the greater the anion-concentration dependence. For instance, the capacitance in the chloride electrolyte is the lowest among the three categories of the electrolytes, and the rest potential is affected only weakly by $\mathrm{Cl}^{-}$concentration with a dependence slope of $5.5 \mathrm{mV} / \mathrm{p}\left[\mathrm{Cl}^{-}\right]$(Fig. 8). This is consistent with finding that, as discussed earlier, show the specific capacitance in sodium chloride to be close to that predicted by the space-charge capacitance, which involves

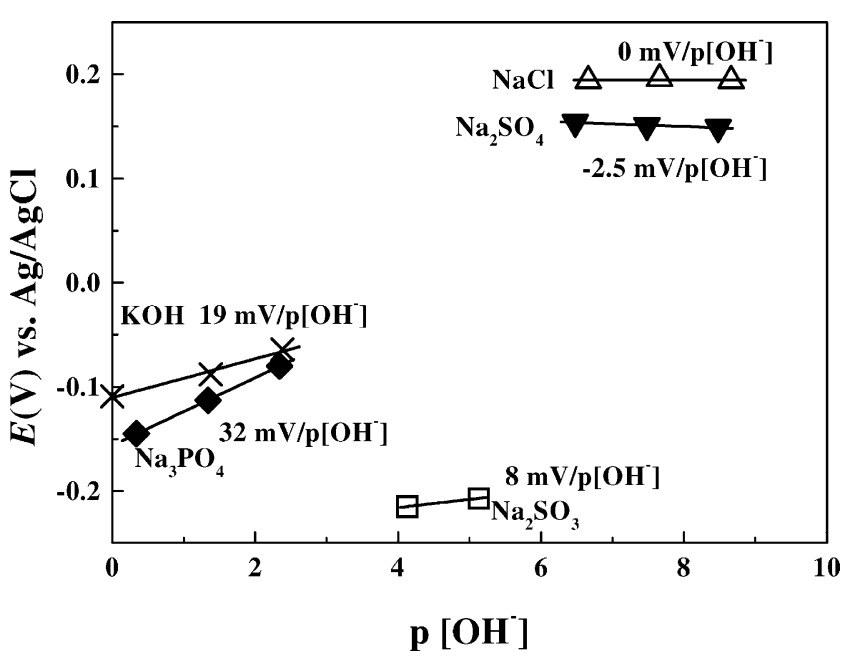

Fig. 9. Effect of alkalinity of electrolyte on rest potential of mixed electrode containing magnetite:carbon black 9:1 $\left(\mathrm{p}\left[\mathrm{OH}^{-}\right] \equiv-\log \left[\mathrm{OH}^{-}\right]\right)$.

no redox reaction and hence a weak dependence on $\mathrm{Cl}^{-}$ concentration.

Potassium hydroxide, which gives the intermediate specific capacitance among the three groups of the electrolytes employed (Table 1) displays an intermediate dependence on anion $\left(\mathrm{OH}^{-}\right)$concentration, with a dependence slope of $19 \mathrm{mV} / \mathrm{p}\left[\mathrm{OH}^{-}\right]$. It is noted that the solution alkalinity (or acidity) has a strong effect on rest potential only under extremely alkaline conditions (e.g. $\mathrm{p}\left[\mathrm{OH}^{-}\right]<3$ ), such as in $\mathrm{KOH}$ and sodium phosphate electrolytes (Fig. 9), but has little effect for the rest electrolytes, which have a $\mathrm{p}\left[\mathrm{OH}^{-}\right]>4$.

The strongest correlation is observed for $\mathrm{SO}_{3}{ }^{2-}$, which, as described earlier, clearly exhibits pseudo-capacitance. The dependence slope is $28 \mathrm{mV} / \mathrm{p}\left[\mathrm{SO}_{3}{ }^{2-}\right]$. The magnitude of the slope is close to the well-defined Nernstian slope $(30 \mathrm{mV})$ for a redox reaction that involves an electron-to-anion ratio of 2. Meanwhile, the positive sign of the slope implies that the anion and electron are involved on the opposite sides of the potential-determining reaction. It is also worth mentioning that the rest potentials of a pure $\mathrm{CB}$ electrode show a complete different, weak dependence. In view of these results, two pseudo-capacitance reaction mechanisms are possible for $\mathrm{Na}_{2} \mathrm{SO}_{3}$ electrolyte.

$$
\begin{aligned}
& \mathrm{FeO}+\mathrm{SO}_{3}{ }^{2-} \leftrightarrow \mathrm{FeSO}_{4}+2 \mathrm{e}^{-} \\
& 2 \mathrm{Fe}^{\mathrm{II}} \mathrm{O}+\mathrm{SO}_{3}{ }^{2-} \leftrightarrow\left(\mathrm{Fe}^{\mathrm{III}} \mathrm{O}\right)^{+} \mathrm{SO}_{3}{ }^{2-}\left(\mathrm{Fe}^{\mathrm{III}} \mathrm{O}\right)^{+}+2 \mathrm{e}^{-}
\end{aligned}
$$

Reaction (1) suggests possible surface redox reactions of sulphur in the form of sulphate and sulphite anions. Reaction (2), on the other hand, suggests possible redox reactions between $\mathrm{Fe}^{\mathrm{II}}$ and $\mathrm{Fe}^{\mathrm{III}}$ accompanied by intercalation of sulphite ions to balance the extra charge within the iron oxide layers. The presence of the compact hydroxide surface-layer of the nanocrystallites might facilitate the intercalation reaction [17]. Both mechanisms indicate the reactions occur only at the surface region, as the conductiv- 
ity of the oxide would decrease dramatically when $\mathrm{Fe}^{3+}$ forms. The mechanisms are tentative, and although they are consistent with the rest potential behaviour have yet to be tested against other spectroscopic studies.

In summary, the capacitive behaviour of magnetite in aqueous electrolytes including sodium sulphite, sulphate, chloride and phosphate, and potassium hydroxide has been characterised, and are categorised into three groups. Sodium sulphate and chloride electrolytes give capacitances $(\sim 5 \mathrm{~F} /$ $\mathrm{g}-\mathrm{Fe}_{3} \mathrm{O}_{4}$ ) close to the space-charge capacitance of the oxide. Potassium hydroxide and sodium phosphate yield a higher capacitance $(\sim 7 \mathrm{~F} / \mathrm{g})$ which can be attributed, at least in part, to a surface redox reaction which involves hydroxide ions. Sodium sulphite results in the highest capacitance which, depending on the dispersion of the magnetite crystallites on the conductive matrix, reaches as high as $510 \mathrm{~F} / \mathrm{g}-\mathrm{Fe}_{3} \mathrm{O}_{4}$ with an operation voltage range of $1.2 \mathrm{~V}$. Redox reactions which involve sulphite ions within the surface-layer of magnetite crystallites have been proposed and are based on a correlation between rest potential and anion-concentration.

\section{Acknowledgements}

The work was partly supported by the National Science Council of Republic of China under contract number NSC89-2214-E-002-016.

\section{References}

[1] B.E. Conway, J. Electrochem. Soc. 138 (1991) 1539

[2] S. Sarangapani, B.V. Tilak, C.-P. Chen, J. Electrochem. Soc. 143 (1996) 3791.

[3] S. Trasatti, G. Buzzanca, J. Electroanal. Chem. Interf. Electrochem. 29 (1971) App. 1.

[4] D.L. Burke, O.J. Murphy, J.F. O'Neill, S. Venkatesan, J. Chem. Soc., Faraday Trans. I 73 (1977) 1659.

[5] B.E. Conway, V. Birss, J. Wojtowicz, J. Power Sources 66 (1 997) 997) 1.

[6] J.P. Zheng, T.R. Jow, J. Electrochem. Soc. 142 (1995) L6.

[7] J.W. Ling, K.E. Swider, C.I. Merzbacher, D.R. Rolison, Langmuir 15 (1999) 780.

[8] D.C. Grahame, Chem. Rev. 41 (1947) 441.

[9] M.A.V. DeVanathan, B.V.K.S.R.A. Tilak, Chem. Rev. 65 (1965) 635.

[10] V. Srinivasan, J.W. Weidner, J. Electrochem. Soc. 144 (1997) L210.

[11] T.-C. Liu, W.G. Pell, B.E. Conway, S.L. Roberson, J. Electrochem. Soc. 145 (1998) 1882.

[12] H.Y. Lee, J.B. Goodenough, J. Solid State Chem. 144 (1999) 220.

[13] H.Y. Lee, J.B. Goodenough, J. Solid State Chem. 148 (1999) 81.

[14] L.R. Shiue, N.L. Wu, D.S. Wu, Y.P. Lan, PCT (Patent Cooperation Treaty)/US01/00756.

[15] N.L. Wu, Nanocrystalline oxide supercapacitors, Mater. Chem. Phys. 75 (2002) 6.

[16] C. Tsouris, D.W. DePaoli, J.T. Shor, US Patent 6,179,987 B1 (2001).

[17] R.M. Cornell, U. Schwertmann, The Iron Oxides, VCH, Weinheim, Germany, 1996.

[18] S.R. Morrison, Electrochemistry at Semiconductor and Oxidized Metal Electrodes, Plenum Press, New York, 1980, pp. 126-133.

[19] N.L. Wu, J.Y. Hwang, P.Y. Liu, C.Y. Han, S.L. Kuo, K.H. Liao, M.H. Lee, S.Y. Wang, J. Electrochem. Soc. 148 (2001) 550. 